\title{
A 1960s guide to treating child patients
}

The following two archive pieces are excerpts from J. Miller's booklet

Dentistry for children published by the British Dental Association (BDA)

in 1962. The booklet was based on a series of 11 articles on paediatric

dentistry that appeared in the BDJ in Volumes 112 and 113.

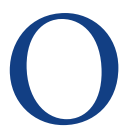
ne of the reasons given by practitioners for not treating children is the so-called 'difficulty of handling the children'. This concept is due to those children who do not visit a dentist until they are in pain or who have heard frightening tales of dentistry and are thus abnormal from a behaviour point of view. A child should make his first visit to the dentist well before any treatment is anticipated, preferably at a routine visit paid by the mother. If a child attends as part of a full family practice there should be little or no caries at the first visit, for the mother will have been instructed, whilst pregnant, on the care of the child's mouth.

\section{'The value of a small chair in the waiting room, suitable for a 3-year- old, is often underestimated.'}

However, all children are not introduced to dentistry under ideal conditions and the practitioner has to be prepared to tackle a variety of behaviour patterns which range from high spirits with co-operation to temper without co-operation. There are no hard-and-fast rules which may be used with a guarantee of success every time but there are general lines to be followed which will help greatly. For the purpose of describing these we will assume that the child is age 3; there is little purpose in starting routine visits much earlier than this age and for treatment to commence after the age of 4 to 5 years presents more problems of behaviour and treatment than can be described in a short series.

The young patient rapidly picks up his mood from the people he is with; if the parents are nervous he will be nervous. He will quickly sense whether the staff are used to children or not - staff that are prepared to receive children will be more confident; thus, before the child comes, arrangements for a small patient must be made. The value of a small chair in the waiting room, suitable for a 3-year-old, is often underestimated. One need not provide a whole range of chairs for each size of child, but one for that important first visit, at 3 , together perhaps with a table, is most useful. Children's books and comics are helpful. Toys, in general, are

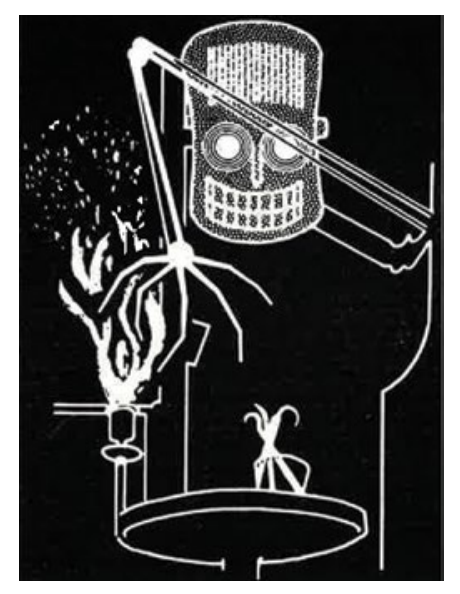

Fig. 1 Child's impression of dental equipment

firm handling and exceptions to it are babies [and children with disabilities]. The appointment for a child must be kept, for a waiting child is an apprehensive child. A seated operator is less frightening than a standing one, and it is often helpful if the surgery assistant carries a small patient into the surgery; dental equipment can appear very terrifying from any angle let alone from floor level (Fig. 1). [...]

of more nuisance than help for they have to be left at the surgery after treatment; this can be difficult. Opinion differs on whether an aquarium is more effective in the surgery or the waiting room, but it certainly is of value. In the surgery special arrangements are made; where small instruments are available they should be used, for example, miniature handpieces and burs, small-size cotton-wool rolls and saliva ejectors, a special dental chair or adaptor. [...]

After the first view of dentistry with a parent, all subsequent visits to the surgery should be alone, with parents remaining in the waiting room. This may require some

\section{Prevention of Formation of the Mass of} Food Debris in Stagnation Areas This may be achieved by dietary methods of cleansing once the child has enough molars to chew apples; that is, from the time the first deciduous molars are present. Up to this time the child's mother has to use some method, either lint or a baby's toothbrush to keep the front teeth clean. Once the child can chew, an apple in either slices or quarters will clean the teeth. Figures 2, 3,4 and 5 show how apple cleans away a chocolate biscuit. A mother can try this for herself. The important thing is the 
14 timing of the cleansing either by apple or brushing. Most damage occurs if food debris is left undisturbed on the teeth for a long time, for example, during sleep; cleaning before sleep is most important. Ideally it should be done after every meal but failing that, the last thing before sleep. Bubble-and-swallow methods of mouth cleansing can be used after meals. Provided the method is started before the second deciduous molar erupts, food debris can be kept to a minimum on the distal surface of the first deciduous molar. If food debris collects behind the first deciduous molar, caries may commence in the distal surface of that tooth before the second molar has erupted and will spread to the mesial surface of the second molar as it erupts. [...]

Thus, the deciduous teeth are kept clean by chewing and rinsing measures which the child can carry out itself. Brushing to remove the apple from gums and teeth encourages the habit of the brush but is of minor value in cleaning the teeth of infants.

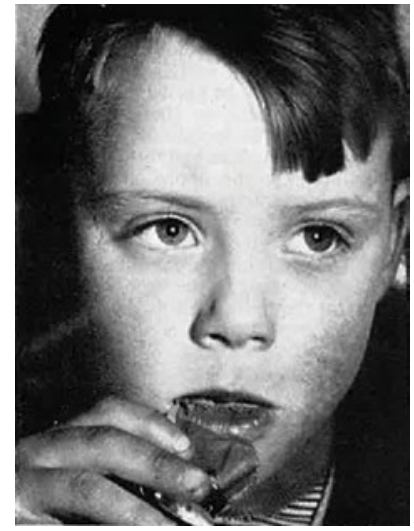

Fig. 2 Boy eating chocolate biscuit

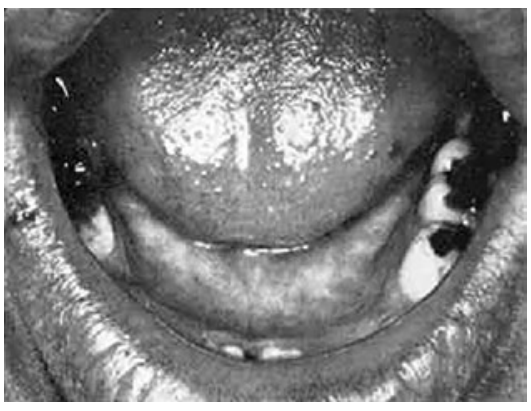

Fig. 4 Appearance of teeth of boy in Figure 2

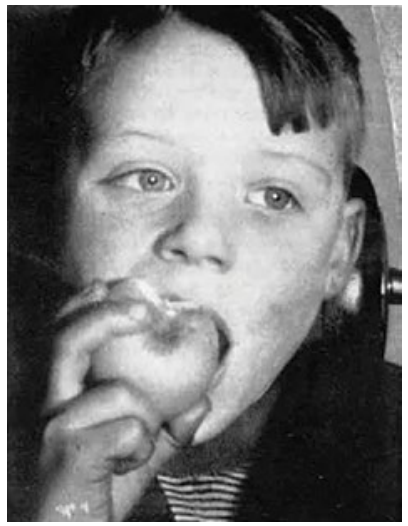

Fig. 3 Same boy with apple

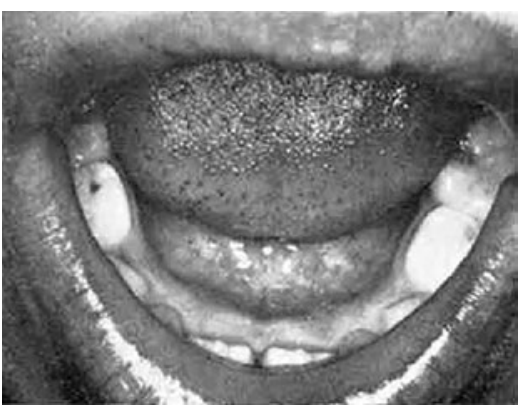

Fig. 5 Appearance of teeth after the chewing of one bite of apple following Figure 3

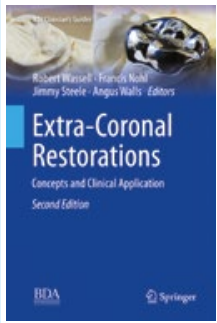

\section{EXTRA-CORONAL RESTORATIONS: CONCEPTS AND CLINICAL APPLICATION, SECOND EDITION}

Robert Wassell, Francis Nohl, Jimmy Steele, Angus Walls

2019; Springer;

price f139.99; pp. 463

ISBN: 9783319790923

I enjoyed reading this book of over 450 pages, with its well-written detail and useful information, much of it sensible advice and good guidance. There are useful references in each chapter encouraging further reading and a deeper understanding. The book covers a broad range of topics from clinical performance to managing risk, and also provides a look at immunological reactions and materials. Chapters on aesthetics, implant crowns and expected techniques for crowning teeth are also included.

This is a well-produced book with easy to follow text. There are a good number of diagrams and images and, despite the lack of clinical cases and a few unnecessary images, these supplement the text well.

The first third of the book provides an overview of the basics of general dentistry including short summaries of caries, endodontics, periodontal disease (using the old classification) and tooth wear. Unfortunately, the three pages dedicated to 'What is TSL' is possibly too brief to be of much value. This first part of the book is not particularly relevant to extra-coronal restorations but it is a good overview of many interesting topics in clinical dentistry which could be seen as additional content rather than irrelevant to the topic suggested by the title of the book. If the first third does frustrate some perhaps more experienced clinicians, then I suggest they go straight to the chapter on occlusal control, which is a gem. This chapter repeats one of the authors' excellent previously published table on seven ways to achieve occlusal space, now reduced to six ways.

Once the content gathers momentum beyond the 11 chapters, 'A healthy start' and 'Managing future risk', it takes off and this is where most clinicians will enjoy the detail. The latter chapters are particularly useful for those looking for techniques leading to a very good ending on retrofitting crowns to existing dentures. There is a good discussion outlining the benefits of provisional restorations, but some of the general restorative techniques such as impression recording is rather basic and not particularly up to date. There is, however, excellent advice on aspects such as the use of posts, cores and ferrules.

Given the title extra-coronal restorations, the book ends its journey a little prematurely as some newer and frequently discussed concepts such as vertical margins, BOPT (biologically-oriented preparation technique), contemporary core techniques, and the current options available through the application of digital dentistry are not given enough discussion.

This attractive book provides good and relevant information on much more than crowns and is available both as hardback and online, no doubt providing something for undergraduates and clinicians at all stages of their career.

Brian Millar 